\title{
Symptomatic Hemorrhage Associated With Recurrent Pilocytic Astrocytoma With Granulation Tissue
}

\author{
-Case Report-
}

\author{
Takashi SHINGU, Yasuhiko AKIYAMA, Mitsuhiro DAISU, Nobuyuki MARUYAMA, \\ Yoshifumi MATSUMOTO, Takeshi MIYAZAKI, Hidemasa NAGAI, \\ Yoshiaki YAMAMOTO, Toshiki YAMASAKI, Manabu YOSHIDA*, \\ Riruke MARUYAMA*, and Kouzo MORITAKE
}

Department of Neurosurgery and *Pathology Laboratory, Shimane University

School of Medicine, Izumo, Shimane

\begin{abstract}
A 51-year-old woman had been followed up for 10 years for recurrence of pilocytic astrocytoma 5 years after the initial treatment consisting of subtotal resection, chemotherapy, and radiation therapy. The patient presented with sudden onset of headache and vomiting. Computed tomography and $\mathrm{T}_{2}{ }^{*}$-weighted magnetic resonance imaging revealed hemorrhage in the tumor located in the right basal ganglia, thalamus, and hypothalamus. She underwent gross total resection of the lesion. Histological examination confirmed recurrent pilocytic astrocytoma with organizing hematoma and granulation tissue. Although neither symptomatic hemorrhage nor late benign recurrence is common, careful long-term follow up is necessary for patients with pilocytic astrocytoma.
\end{abstract}

Key words: supratentorial astrocytoma, pilocytic astrocytoma, hemorrhage, recurrence, magnetic resonance imaging

\section{Introduction}

Pilocytic astrocytoma is a benign tumor that most commonly occurs during the first two decades of life. ${ }^{5)}$ These tumors occur at all levels of the neuraxis, including the cerebellum, optic nerve, optic chiasm/hypothalamus, thalamus, brain stem, spinal cord, and cerebral hemisphere containing the basal ganglia.5) Pilocytic astrocytoma is a slow-growing tumor, and gross total or subtotal resection without adjuvant therapy results in good outcome in most patients, although several cases of late recurrence have been described, including as long as 36 and 45 years after surgical treatment., ${ }^{1,4,6,9,14,29)}$ Pilocytic astrocytomas are frequently associated with cysts that occasionally contain xanthochromic or brown fluid suggesting old hemorrhage. ${ }^{5,30)}$ However, symptomatic hemorrhage related to pilocytic astrocytoma is rare.

We describe a case of recurrent pilocytic astrocytoma with organizing hematoma and granulation

Received January 4, 2006; Accepted March 8, 2007 tissue manifesting as symptomatic intratumoral hemorrhage 15 years after the initial treatment.

\section{Case Report}

A 35-year-old woman presented with progressive muscle weakness of the left lower limb in 1986. Computed tomography (CT) revealed a cystic lesion with an enhanced portion located in the right temporal lobe, basal ganglia, and hypothalamus (Fig. 1A, B). She was referred to our hospital, and underwent subtotal resection of the tumor and placement of an Ommaya reservoir in 1987 (Fig. 1C). The mural nodule was not well demarcated so could not be resected completely. Histological examination revealed a biphasic pattern of growth, with compact portions consisting of bipolar astrocytic tumor cells associated with Rosenthal fibers, and cystic zones comprised of multipolar cells (Fig. 2A, B). The diagnosis was pilocytic astrocytoma. Adjuvant therapy consisting of chemotherapy with 1-(4-amino-2methyl-5-pyrimidinyl)-methyl-3(2-chlorethyl)-3-nitrosourea (ACNU) and vincristine and radiation ther- 

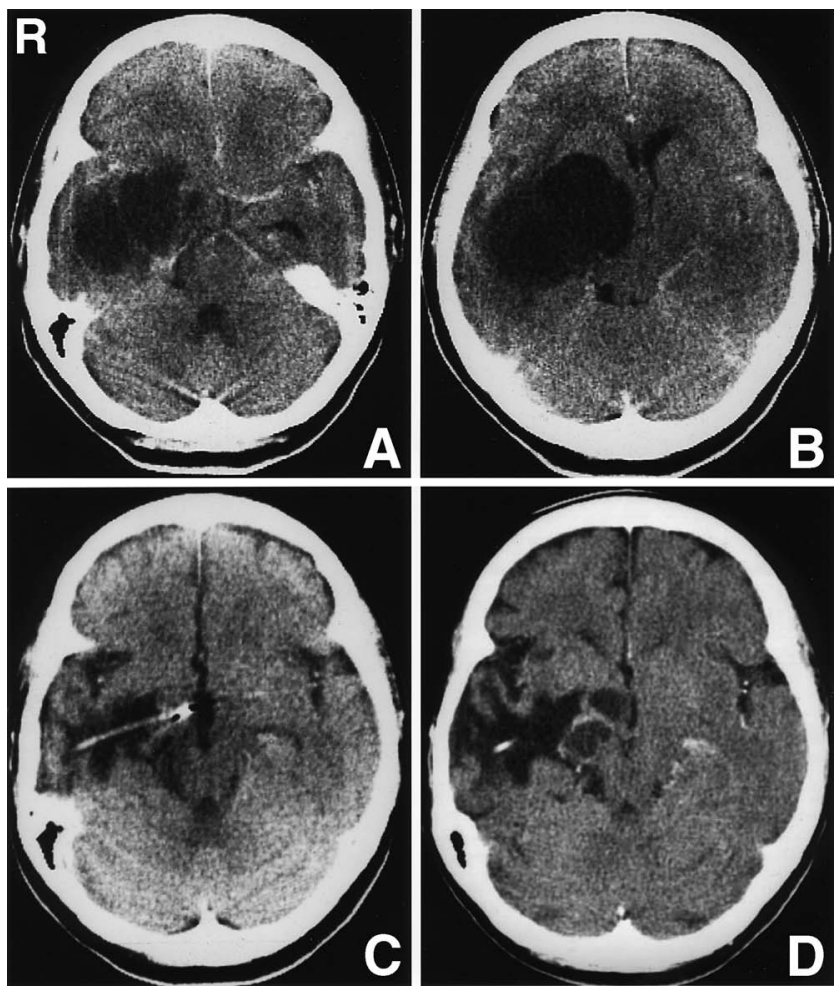

Fig. 1 A, B: Preoperative computed tomography (CT) scans on first admission in 1986 demonstrating a cystic lesion with an enhanced portion in the right temporal lobe, ipsilateral basal ganglia, and hypothalamus. C: Postoperative CT scan obtained in 1987 showing remarkable reduction in the tumor and the tube connected with the Ommaya reservoir. D: Follow-up CT scan 5 years after the initial treatment demonstrating a mass lesion with cystic portions and partially enhanced wall.

apy (50 Gy) was performed. She was discharged in 1987 with left hemiparesis, left hemisensory disturbance, and left homonymous hemianopsia.

CT revealed no mass lesion with enhancement 18 months after the treatment. However, follow-up CT demonstrated a multicystic lesion with partial enhancement, indicating recurrence of pilocytic astrocytoma, 5 years after the initial treatment (Fig. 1D). Further follow-up CT and magnetic resonance (MR) imaging revealed slow growth of the tumor without neurological worsening. Since the patient exhibited allergic responses to various drugs possibly required after surgical treatment, including anticonvulsants and antibiotics, we decided to observe the patient carefully as long as no neurological deterioration occurred. The patient had not experienced symptoms attributable to intracranial
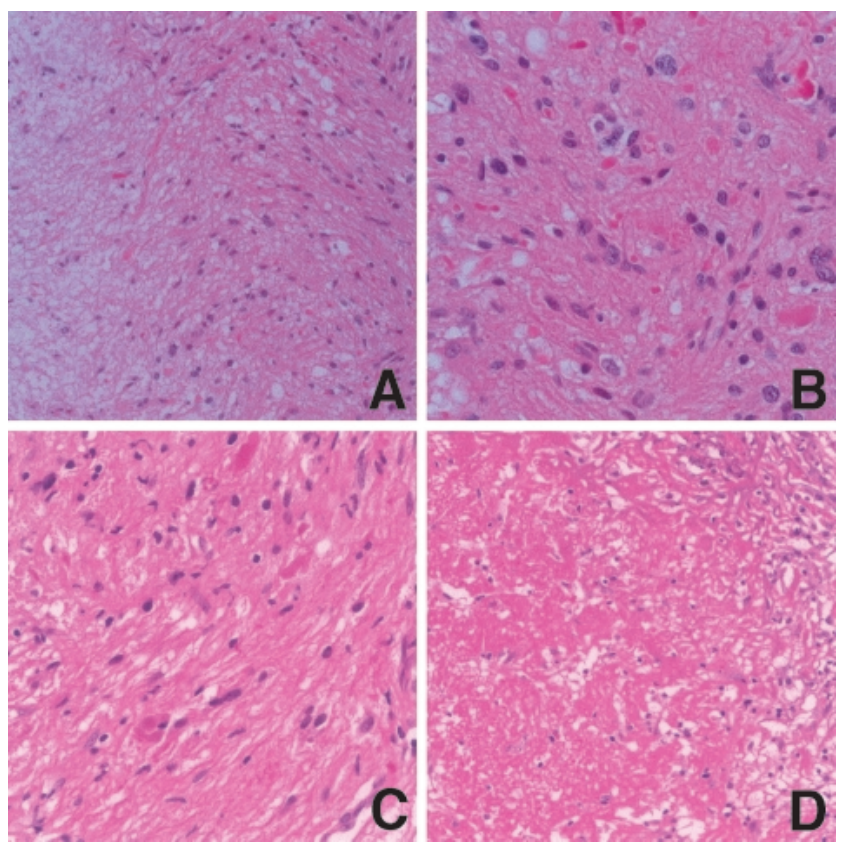

Fig. 2 A, B: Photomicrographs of the tumor obtained at the initial operation in 1987 showing biphasic pattern of growth (A: hematoxylin and eosin [HE] stain, $\times 100$ ), consisting of cystic zones made of multipolar cells, and compact portions consisting of bipolar astrocytic tumor cells associated with Rosenthal fibers (B: HE stain, $\times 400$ ). C, D: Photomicrographs of the recurrent tumor resected in 2002 consisting of compact portions including pilocytic cells and Rosenthal fibers (C: HE stain, $\times 200$ ) similar to the previous specimen, and degenerative tissue with organizing hematoma (D: HE stain, $\times 100$ ).

bleeding for 10 years.

The patient suffered sudden onset of severe headache and vomiting on January 20, 2002, and was brought to our hospital on February 1. Neurological examination revealed no apparent worsening of left hemiparesis, left hemisensory disturbance, and left homonymous hemianopsia. CT demonstrated a high density area in the tumor (Fig. $3 \mathrm{~A}$ ). $\mathrm{T}_{2}{ }^{*}$ weighted MR imaging showed a hypointense region within this area indicating hemosiderin (Fig. 3B), which appeared as hyperintense on $\mathrm{T}_{1}$-weighted $\mathrm{MR}$ imaging and hypointense and hyperintense on $\mathrm{T}_{2}$-weighted MR imaging suggesting methemoglobin and free methemoglobin, consistent with the components of subacute hemorrhage (Fig. 3C, D). $\mathrm{T}_{1^{-}}$ weighted MR imaging revealed a mass lesion including a cystic portion appearing hyperintense to the cerebrospinal fluid and a solid portion with 

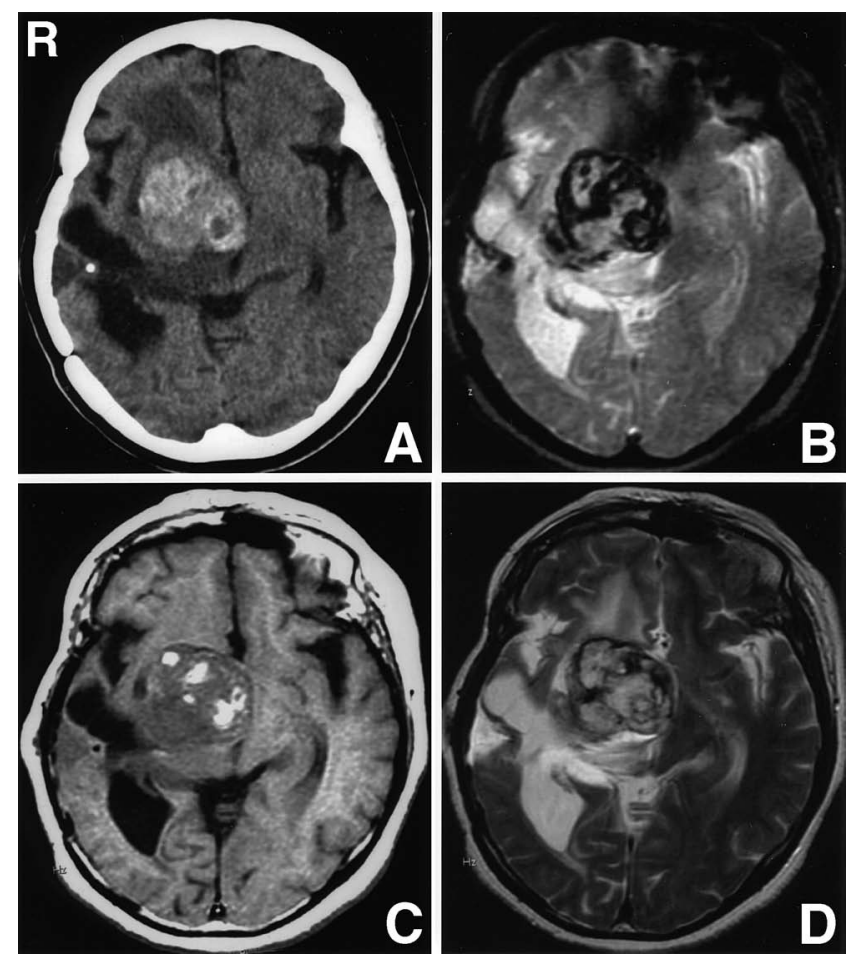

Fig. 3 A: Computed tomography scan demonstrating a high density area in the tumor suggesting intratumoral hemorrhage. $\mathrm{B}: \mathrm{T}_{2}{ }^{*}$ weighted magnetic resonance (MR) image revealing intratumoral hypointensity indicating hemosiderin in the subacute or chronic hematoma. C, D: $\mathrm{T}_{1}$-weighted MR image showing hyperintensity $(C)$, and $T_{2^{-}}$ weighted MR image showing hypointensity and hyperintensity (D) consistent with the mixture of methemoglobin and free methemoglobin in the subacute hemorrhage.

heterogeneous enhancement after administration of gadolinium-diethylenetriaminepenta-acetic acid (Gd-DTPA) (Fig. 4A-C). Angiography was not performed because of the allergic response to contrast agent containing iodine, although no iodine hypersensitivity had been found at the initial treatment.

Surgical resection of the tumor via the zygomatic approach was performed on May 20, 2002. The tumor was removed piecemeal along the tube of the Ommaya reservoir that had been placed at the initial operation. The cyst content was xanthochromic fluid, suggesting previous hemorrhage. The solid portion of the tumor was reddish, fibrous, and hard. The tumor was well demarcated, and gross total resection was achieved.

Histological examination revealed that the tumor consisted of bipolar astrocytic cells associated with
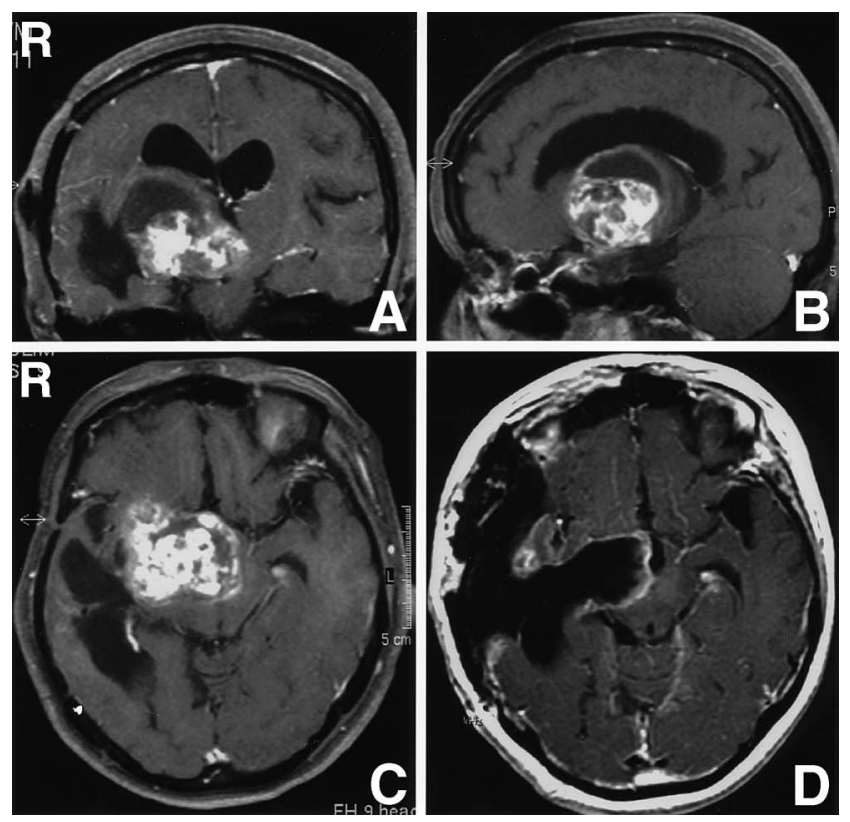

Fig. 4 A-C: Preoperative $T_{1}$-weighted magnetic resonance (MR) images showing a mass in the right basal ganglia, thalamus, and hypothalamus with heterogeneous enhancement after administration of gadoliniumdiethylenetriaminepenta-acetic acid (GdDTPA). D: Postoperative $\mathrm{T}_{1}$-weighted MR image with Gd-DTPA revealing gross total resection of the tumor.

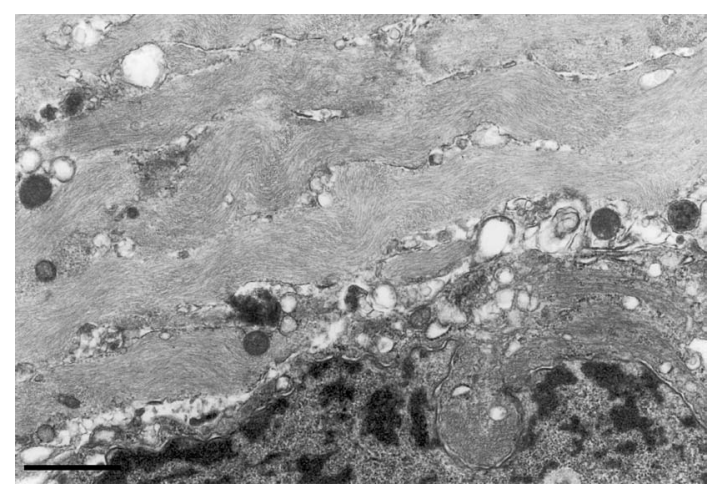

Fig. 5 Electron micrograph showing a tumor cell surrounded by abundant intermediate filaments. Bar $=1 \mu \mathrm{m}$.

Rosenthal fibers (Fig. 2C), resembling the compact portions of the tumor removed at initial operation in 1987 (Fig. 2B), limited to a small part of the lesion, but mainly degenerative tissue with organizing hematoma (Fig. 2D) and granulation tissue. Ultrastructural examination demonstrated abundant intermediate filaments around the tumor cells (Fig. 5). 
Table 1 Cases of supratentorial pilocytic astrocytoma with symptomatic hemorrhage

\begin{tabular}{|c|c|c|c|c|}
\hline Author (Year) & Age (yrs)/Sex & Location & Histology & Outcome \\
\hline Glew $(1977)^{16)}$ & $30 / \mathrm{M}$ & hyp/ITH & grade 1 & dead \\
\hline Charles et al. $(1981)^{8)}$ & $26 / \mathrm{F}$ & optic nerve/ITH & pilocytic & alive \\
\hline Byard et al. $(1991)^{7)}$ & $5 / F$ & chiasm/ITH & low grade & dead \\
\hline Lones and Verity $(1991)^{22)}$ & $69 / F$ & thal, bg/IVH & pilocytic & dead \\
\hline Sorensen et al. $(1995)^{32)}$ & $58 / F$ & hyp/ITH & pilocytic & alive \\
\hline Matsumoto et al. (1997) & $45 / \mathrm{M}$ & hyp/ITH, SAH & pilocytic & alive \\
\hline Golash et al. $(1998)^{17)}$ & $13 / \mathrm{F}$ & hyp/CH, SAH & pilocytic & alive \\
\hline Hwang et al. (1998) ${ }^{19)}$ & $34 / \mathrm{M}$ & hyp/CH, IVH, SAH & pilocytic & alive \\
\hline Aichholzer et al. (2001)2) & $11 / \mathrm{M}$ & chiasm-hyp/ITH, IVH, SAH & pilocytic with AComA aneurysm & alive \\
\hline Devi et al. $(2001)^{12)}$ & $4 / \mathrm{M}$ & third vent/IVH & pilocytic & dead \\
\hline Gottfried et al. (2003) ${ }^{18)}$ & $24 / \mathrm{M}$ & temporal/ITH & pilomyxoid & alive \\
\hline Garg et al. $(2004)^{15)}$ & $13 / \mathrm{M}$ & chiasm-hyp/SAH & pilocytic & alive \\
\hline Present case & $51 / F$ & hyp, thal, bg/ITH & pilocytic & alive \\
\hline
\end{tabular}

AComA: anterior communicating artery, bg: basal ganglia, $\mathrm{CH}$ : cerebral hemorrhage, hyp: hypothalamus, ITH: intratumoral hemorrhage, IVH: intraventricular hemorrhage, SAH: subarachnoid hemorrhage, thal: thalamus, third vent: third ventricle.

Table 2 Cases of cerebellar or brain stem pilocytic astrocytoma with symptomatic hemorrhage

\begin{tabular}{|c|c|c|c|c|}
\hline Author (Year) & Age (yrs)/Sex & Location & Histology & Outcome \\
\hline Mauersberger and Cuevas-Solorzano $(1977)^{24)}$ & $10 / F$ & cerebellum/CH & spongioblastoma & dead \\
\hline Fogelson et al. $(1980)^{13)}$ & $9 / \mathrm{M}$ & cerebellum/CH & pilocytic & alive \\
\hline Specht et al. $(1986)^{33)}$ & $8 / \mathrm{M}$ & cerebellum/ITH & $\begin{array}{l}\text { mixed pilocytic/ } \\
\text { oligodendroglioma }\end{array}$ & dead \\
\hline
\end{tabular}

$\mathrm{CH}$ : cerebellar hemorrhage, ITH: intratumoral hemorrhage.

The diagnosis was recurrent pilocytic astrocytoma with organizing hematoma and granulation tissue. Histological examination revealed no malignant change of the tumor or evidence of angioma.

There were no intraoperative or postoperative complications. Postoperative MR imaging with GdDTPA confirmed gross total resection of the tumor (Fig. 4D). Adjuvant therapy was not performed. The patient was discharged without neurological deterioration in August 2002, and is being followed up with MR imaging at a local clinic without recurrence of the tumor.

\section{Discussion}

Symptomatic hemorrhage associated with pilocytic astrocytoma is rare (Tables 1 and 2). 2,7,8,12,13,15-19,22-25, $32,33,36,37)$ Such hemorrhage was observed in the intratumoral, intracerebral, intracerebellar, ventricular, and subarachnoid spaces, and the outcome was affected more by the extent of bleeding than the location of the tumor or hematoma. $2,7,8,12,13,15-19,22-25,32,33$, 36,37) High-grade gliomas and metastatic lesions bleed from structural abnormalities of the tumor vessels, tumor invasion of vessel walls, and necrosis. ${ }^{18)}$ Although the mechanism that results in hemorrhages in pilocytic astrocytomas is unclear, the bleeding may originate from abnormal vessels with thin walls, endothelial proliferation, retiform capillaries, encased aneurysm, stromal degeneration, stretched brain, infarction, coexisting vascular malformations, or congestive vessels. ${ }^{2,13,15,18,23,25,36,37)}$ Immediate accumulation of large amounts of blood causing sudden onset of signs or symptoms may be rare but repeated microbleeding resulting in slow and gradual expansion of cysts is common in pilocytic astrocytomas, since regressive alterations in histopathology are observed in these tumors. ${ }^{5}$ ) However, subarachnoid hemorrhage (SAH) associated with pilocytic astrocytoma can cause immedi- 
ate headache and vomiting resulting from meningeal stimulation, and disturbance of consciousness from spasm of perforating vessels or compression of brain stem, as well as aneurysmal SAH. ${ }^{15,23)}$ Intraventricular or cerebellar hemorrhage can induce acute hydrocephalus, resulting in headache, vomiting, or lethargy. ${ }^{13,37)}$

The tumor was large in our patient, so compensation for the increased intracranial pressure caused by further enlargement of the lesion was probably inadequate, and a slight increase in tumor size might have caused the sudden headache and vomiting. Expansion of the lesion resulting in the symptoms was mainly due to enlargement of the hematoma, because the histological findings revealed that most of the tumor consisted of organizing hematoma and granulation tissue, indicating that bleeding originated from vessels in the granulation tissue. The granulation tissue could have been caused by microbleeding from the astrocytoma, but radiation can also induce formation of granulation tissue and organizing hematoma. ${ }^{3,5)}$ Both causes were present in this case. Since association of degenerative change with pilocytic astrocytoma is not uncommon, our diagnosis was recurrent pilocytic astrocytoma with organizing hematoma and granulation tissue, even though proliferation of tumor cells may not have been the primary cause of enlargement of the lesion. ${ }^{5)}$

Eight of the 13 patients with supratentorial pilocytic astrocytoma associated with hemorrhage were adults (Table 1), whereas all seven patients with cerebellar or brain stem pilocytic astrocytoma were under 15 years of age (Table 2). The difference in the age distribution with tumor site may reflect the incidence of the tumors, since no biological differences are evident between pilocytic astrocytomas in juvenile patients and adults, or in the cerebellum and cerebrum. ${ }^{5,30}$ The differential diagnosis of angioma from other mass lesions with repeated bleeding in radiological examinations is thought to be difficult since both appear as mixed density and intensity on CT and MR imaging, respectively. ${ }^{28)}$ In addition, the histological findings of pilocytic astrocytoma with hemorrhage are similar to those of angioma. ${ }^{5)}$

Histological examination of almost all of the present lesion found no evidence of angioma but revealed astrocytic tumor cells with organizing hematoma and granulation tissue. Therefore, the histological diagnosis was recurrent pilocytic astrocytoma, although we cannot deny the possibility that angioma had been induced by radiation therapy and then degenerated. Proton MR spectroscopy was not performed in this case. Increased concentration of choline is generally found in primary and secondary brain tumors, and is correlated with the extent of anaplasia. ${ }^{11)}$ Lactate can be detected in ischemic lesion, central necrosis or cyst in tumors, and abscess. Increased fatty acid without increase in choline may indicate necrosis. ${ }^{11)}$ The decrease in N-acetyl-aspartate is thought to be correlated with the malignancy in glioma. ${ }^{20)}$ The peak of choline is absent in cavernous angioma. ${ }^{21)}$ Therefore, MR spectroscopy might have been useful for the differential diagnosis in this case.

Pilocytic astrocytomas are benign tumors that grow slowly, with the exception of pilomyxoid astrocytoma, a more aggressive variant. ${ }^{5,6,18,34)}$ Histopathological changes in pilocytic astrocytomas tend toward regressive changes including hyalinization, telangiectatic vessels, necrosis, or lymphocytic infiltration rather than anaplasia, and malignant transformation is rare. ${ }^{5}$ MIB-1 labeling indices range from $0 \%$ to $3.9 \% .^{5}$ The survival rate of patients with pilocytic astrocytomas is $95.8 \%$ at 10 years. ${ }^{6)}$ The non-aggressive character of pilocytic astrocytoma indicates a favorable prognosis in most patients after gross total or subtotal resection of the tumor without adjuvant therapy. ${ }^{1,4,6,14,30)}$ However, a high incidence of recurrence, ranging from $7 \%$ to $48 \%$, has been reported. ${ }^{10,29,35)}$ In a series of supratentorial pilocytic astrocytomas, $9 \%$ to $20 \%$ of cases showed recurrence within 6-12 years. ${ }^{1,9,14,30)}$ Since late recurrences of cerebellar pilocytic astrocytoma 36 and 45 years after "complete" surgical resection have been reported, late recurrence could also occur in patients with supratentorial pilocytic astrocytoma. ${ }^{4,29)}$

Three patterns of recurrence can be described: early recurrence, within 4 years of initial surgery, which is more likely to be associated with younger age and diffuse histological appearance; late recurrence, which is unrelated to histological features and the extent of surgery and apparently unpredictable; and late and rare recurrence, caused by malignant histological transformation of the tumor. ${ }^{10)}$ Our case can be classified as late recurrence. Three mechanisms of late recurrence have been proposed: true recurrence, which occurs after complete excision of the primary tumor; regrowth of residual tumor after several years of quiescence; and regrowth of residual tumor at an extremely slow rate, in which tumor cells never stop dividing, but cell proliferation is slow, and/or tumor growth is counterbalanced by cell death. ${ }^{4)}$ In our case, followup CT and MR imaging of the recurrent tumor revealed slow enlargement of the lesion, and the histological study after the second operation revealed that the tumor consisted of both tumor cells 
resembling those of primary tumor and degenerative tissue with organizing hematoma and granulation. Therefore, the late recurrence in this case could have been due to slow regrowth of residual tumor with regressive changes.

Postoperative radiotherapy and chemotherapy were performed according to our protocol for gliomas at the time of initial treatment, since tumor resection was subtotal to avoid postoperative neurological deterioration. The efficacy of adjuvant therapy in improving survival rate or inhibiting recurrence has not been substantiated in patients with pilocytic astrocytomas. Adjuvant therapy may be unnecessary in the treatment of pilocytic astrocytomas, since these tumors can be resected or decompressed at recurrence. ${ }^{4)}$ Although radiation therapy may be effective and used for optico-hypothalamic, diencephalic, and brain stem lesions, postoperative radiotherapy seems unnecessary for patients with pilocytic astrocytomas located in other sites. ${ }^{6,14,27)}$ Chemotherapy is effective in patients with pilocytic astrocytomas in the optic pathway and/or hypothalamus or patients younger than 3 years. ${ }^{26,31)}$ However, management of pilocytic astrocytomas generally does not include adjuvant chemotherapy.1,6,14,30) Whether radiotherapy and/or chemotherapy could have been effective in delaying the recurrence in this case remains unknown, but the lesion enlarged in size gradually after these adjuvant therapies. Therefore, long-term follow up is necessary in patients with pilocytic astrocytomas with or without adjuvant therapy, especially if the tumor was not totally removed or a cystic portion was present.

\section{Acknowledgment}

We thank Dr. Makio Kobayashi (PCL Japan, Inc., Tokyo) for the electron microscope study.

\section{References}

1) Afra D, Muller W, Slowik F, Firsching R: Supratentorial lobar pilocytic astrocytomas: report of 45 operated cases, including 9 recurrences. Acta Neurochir (Wien) 81: 90-93, 1986

2) Aichholzer M, Gruber A, Haberler C, Bertalanffy A, Slavc I, Czech T: Intracranial hemorrhage from an aneurysm encased in a pilocytic astrocytoma - case report and review of the literature. Childs Nerv Syst 17: 173-178, 2001

3) Awano T, Kano T, Nagaoka T, Kimura S, Kano T, Kido G, Katayama Y, Kotani A: [A case of cerebral arteriovenous malformation revealing repeated intranidal hemorrhage accompanying neovascularization after stereotactic radiosurgery]. No Shinkei Geka 34: 927-932, 2006 (Jpn, with Eng abstract)
4) Boch AL, Cacciola F, Mokhtari K, Kujas M, Philippon J: Benign recurrence of a cerebellar pilocytic astrocytoma 45 years after gross total resection. Acta Neurochir (Wien) 142: 341-346, 2000

5) Burger PC, Scheithauer BW, Paulus W, Szymas J, Giannini C, Kleihues P: Pilocytic astrocytoma, in Kleihues P, Cavenee WK (eds): Pathology and Genetics of Tumours of the Nervous System. Lyon, IARC Press, 2000, pp 45-51

6) Burkhard C, Patre PLD, Schuler D, Schuler G, Yasargil MG, Yonekawa Y, Lutolf UM, Kleihuse P, Ohgaki H: A population-based study of the incidence and survival rates in patients with pilocytic astrocytoma. J Neurosurg 98: 1170-1174, 2003

7) Byard RW, Bourne AJ, Hanieh A: Sudden and unexpected death due to hemorrhage from occult central nervous system lesions. A pediatric autopsy study. Pediatr Neurosurg 17: 88-94, 1991

8) Charles NC, Nelson L, Brookner AR, Lieberman N, Breinin G: Pilocytic astrocytoma of the optic nerve with hemorrhage and extreme cystic degeneration. Am J Ophthalmol 92: 691-695, 1981

9) Clark GB, Henry JM, McKeever PE: Cerebral pilocytic astrocytoma. Cancer 56: 1128-1133, 1985

10) Davis CH, Joglekar VM: Cerebellar astrocytomas in children and young adults. J Neurol Neurosurg Psychiatry 44: 820-828, 1981

11) Delorme S, Weber MA: Applications of MRS in the elevation of focal malignant brain lesions. Cancer Imaging 6: 95-99, 2006

12) Devi BI, Shukla D, Bhat D, Santosh V: Hypothalamic tumour with haemorrhage. Childs Nerv Syst 17: 567-569, 2001

13) Fogelson MH, Oppenheim RE, McLaurin RL: Childhood cerebellar astrocytoma presenting with hemorrhage. Neurology 30: 669-670, 1980

14) Forsyth PA, Shaw EG, Scheithauer BW, O'Fallon JR, Layton DD, Katzmann JA: Supratentorial pilocytic astrocytomas: a clinicopathologic, prognostic, and flow cytometric study of 51 patients. Cancer 72: 1335-1342, 1993

15) Garg A, Chugh M, Gaikwad SB, Chandra SP, Gupta V, Mishra NK, Sharma MC: Juvenile pilocytic astrocytoma presenting with subarachnoid hemorrhage. Case report and review of the literature. J Neurosurg 100(5 Suppl Pediatrics): 525-529, 2004

16) Glew WB: Stimulated pituitary apoplexy: report of an unusual cause due to hemorrhage into hypothalamic astrocytoma. Ann Ophthalmol 9: 139-142, 1977

17) Golash A, Thorne J, West CG: Low grade pilocytic astrocytoma presenting as a spontaneous intracerebral hemorrhage in a child. Br J Neurosurg 12: 59-62, 1998

18) Gottfried ON, Fults DW, Townsend JT, Couldwell WT: Spontaneous hemorrhage associated with a pilomyxoid astrocytoma: case report. J Neurosurg 99: 416-420, 2003

19) Hwang SL, Huang TY, Chai CY, Howng SL: Hypothalamic juvenile pilocytic astrocytoma presenting with intracerebral hemorrhage. J Formos 
Med Assoc 97: 784-787, 1998

20) Izumiyama $H$, Abe T, Tanioka D, Fukuda A, Kunii N: Clinicopathological examination of glioma by proton magnetic resonance spectroscopy background. Brain Tumor Pathol 21: 39-46, 2004

21) Kinoshita Y, Ota K, Hashimoto M, Yokota A: [Proton magnetic resonance spectroscopy of cavernous sinus hemangioma: possibility for differentiated diagnosis from meningioma]. No To Shinkei 55: 992-993, 2003 (Jpn)

22) Lones MA, Verity MA: Fatal hemorrhage in a cerebral pilocytic astrocytoma-adult type. Acta Neuropathol (Berl) 81: 688-690, 1991

23) Matsumoto K, Akagi K, Abekura M, Maeda $Y$, Kitagawa M, Ryujin H, Iwasa N: Hypothalamic pilocytic astrocytoma presenting with intratumoral and subarachnoid hemorrhage: case report. Neurol Med Chir (Tokyo) 37: 849-851, 1997

24) Mauersberger W, Cuevas-Solorzano JA: Spontaneous intracerebellar hematoma during childhood caused by spongioblastoma of the IVth ventricle. Neuropadiatrie 8: 443-450, 1977

25) Mesiwala AH, Avellino AM, Roberts TS, Ellenbogen RG: Spontaneous cerebellar hemorrhage due to a juvenile pilocytic astrocytoma: case report and review of the literature. Pediatr Neurosurg 34: 235-238, 2001

26) Moghrabi A, Friedman HS, Burger P, Tien R, Oaks WJ: Carboplatin treatment of progressive optic pathway gliomas to delay radiotherapy. J Neurosurg 79: 223-227, 1993

27) Nitta T, Sato K: [A clinicopathological study of 16 cases with optico-hypothalamic glioma]. No Shinkei Geka 23: 217-222, 1995 (Jpn, with Eng abstract)

28) Okuno S, Hisanaga M, Miyasaki A, Tsunoda S, Sakaki T: [Chronic encapsulated hematoma associated with cavernous angioma: case report and review of the literature]. No Shinkei Geka 21: 655-659, 1993 (Jpn, with Eng abstract)

29) Pagni CA, Giordana MT, Canavero S: Benign recurrence of a pilocytic cerebellar astrocytoma 36 years after radical removal: case report. Neurosurgery 28: 606-609, 1991
30) Palma L, Guidetti B: Cystic pilocytic astrocytomas of the cerebral hemispheres: surgical experience with 51 cases and long-term results. J Neurosurg 62: 811-815, 1985

31) Silva MM, Goldman S, Keating G, Marymont MA, Kalapurakal J, Tomita T: Optic pathway hypothalamic gliomas in children under three years of age: the role of chemotherapy. Pediatr Neurosurg 33: 151-158, 2000

32) Sorensen EJ, Silbert PL, Benarroch EE, Jack CR, Parisi JE: Transient amnestic syndrome after spontaneous haemorrhage into a hypothalamic pilocytic astrocytoma. J Neurol Neurosurg Psychiatry 58: 761-763, 1995

33) Specht CS, Pinto-Lord C, Smith TW, DeGirolami U, Suran E, Marshall PC, Davidson RI: Spontaneous hemorrhage in a mixed glioma of the cerebellum: case report. Neurosurgery 19: 278-281, 1986

34) Tihan T, Fisher PG, Kepner JL, Godfraind C, McComb RD, Goldthwaite PT, Burger PC: Pediatric astrocytomas with monomorphous pilomyxoid features and a less favorable outcome. J Neuropathol Exp Neurol 58: 1061-1068, 1999

35) Undjian S, Morinov M, Georgiev K: Long-term follow-up after surgical treatment of cerebellar astrocytomas in children. Childs Nerv Syst 5: 99-101, 1989

36) Van Ouwerkerk WJ, Dirven CM: Hematoma in a low grade medullary astrocytoma: report of an unusual case and literature review. Childs Nerv Syst 14: 742-746, 1998

37) Vincent FM, Bartone JR, Jones MZ: Cerebellar astrocytoma presenting as a cerebellar hemorrhage in a child. Neurology 30: 91-93, 1980

Address reprint requests to: Takashi Shingu, M.D., Department of Neurosurgery, Shimane University School of Medicine, 89-1 Enya-cho, Izumo, Shimane 693-8501, Japan.

e-mail: nogeka@med.shimane-u.ac.jp 